\title{
Protofeminismo y masonería, factores influyentes en la España Contemporánea (1868-1900)
}

\author{
Protofeminism and Freemasonry, influential factors in contemporary \\ Spain (1868-1900)
}

\author{
Miriam Roma García \\ Universidad de Lleida, España \\ miriamromag@gmail.com
}

Recepción: 17 de junio de 2017/Aceptación: 15 de noviembre de 2017 doi: https://doi.org/10.15517/rehmlac.v9i2.28049

Palabras clave

Masonería; logia de adopción; feminismo; siglo XIX; Concepción Arenal.

Keywords

Freemasonry; Adoption lodge; Feminism; XIX century; Concepción Arenal.

Resumen

A partir de la Revolución La Gloriosa (1868) surgieron diferentes voces críticas con la situación y la condición de la mujer tanto por parte de hombres como por parte de mujeres y se desarrollaron durante buena parte del siglo XIX y posteriores. Estas voces fueron las que impulsaron proyectos educativos dedicados a dignificar a la población femenina. Muchos de estos proyectos fueron impulsados desde sectores como la masonería. Por ello, el presente trabajo se dedica a la búsqueda entre la relación del protofeminismo y la masonería del siglo XIX. De esta manera, se estudia, brevemente, la figura de Concepción Arenal como una de las impulsoras que asentó las bases del feminismo que se desarrollaría en España durante el siglo XX a partir de la fundación de diferentes proyectos vinculados a la masonería.

\section{Abstract}

After La Gloriosa Revolution (1868), different critical voices emerged, from both the male and female sector, against the situation and status of women, both from the male and the female sector. Those voices promoted projects for the education of women in order to dignify them and to make them become free people. Many of these projects were initiated by sectors of Freemasonry. Thus, this study aims to explore the connection between protofeminism and Freemasonry in the $19^{\text {th }}$ century. Thus, a case study has been conducted on the leading figure Concepción Arenal as a promoter who laid the foundations of feminism, which would further develop during the $20^{\text {th }}$ century after the founding of several projects, she established by means of her relationships with people linked to Freemasonry.

\section{Introducción}

No se puede entender el nacimiento del feminismo que se desarrollaría durante el siglo XIX sin conocer sus cimientos. Es por ello que en el presente trabajo, se hará un estudio sobre el protofeminismo, entendido como aquellas primeras voces críticas que cuestionaron la situación de dependencia y analfabetismo de las mujeres en general. 
Además, es de suma importancia para el nacimiento del feminismo en España la presencia de amplios sectores de la masonería en la difusión de proyectos para dignificar y acabar con la falta de educación entre la población femenina. Es por este motivo, que el presente trabajo pretende buscar la relación entre el feminismo y la masonería a partir de la Revolución de La Gloriosa que inició el periodo del Sexenio Democrático, el cual trajo consigo importantes cambios en la implantación del liberalismo en España.

¿Contribuyó la masonería en el desarrollo del protofeminismo o fue un proceso paralelo que no tuvo ningún vínculo importante? El presente trabajo se centrará, en toda su extensión, principalmente, en resolver esta cuestión y en la última parte, he creído imprescindible el estudio de caso de la relación de la figura de Concepción Arenal para poder corroborar con firmeza las conclusiones extraídas sobre la relación entre la masonería y el movimiento en defensa de los derechos de las mujeres desarrollado a partir de 1868.

\section{Contexto histórico}

A lo largo del siglo XIX, en el estado español, hubo varios intentos de implantación de un Estado Liberal. Estos intentos se iniciaron el año 1812, año en que se promulgó la primera Constitución española, y duraron hasta el año 1875, cuando se inició la Restauración Borbónica. Durante este periodo, los diferentes gobiernos redactaron varias constituciones con las que se pretendía implantar los principios liberales de libertad, igualdad y fraternidad de la ciudadanía. En este trabajo se centra la atención básicamente en el principio de igualdad; entendida, en este caso como la relación de la igualdad delante de la ley por razones de sexo. La ausencia de esta reivindicación en las diferentes constituciones significó el cuestionamiento de la igualdad jurídica (uno de los cimientos de una sociedad liberal) por parte de mujeres relevantes y también de hombres, que elogiaron y buscaron establecer una función social y moral a las mujeres durante el siglo XIX.

Los primeros intentos de implantación del liberalismo en España, a través de la promulgación de la Constitución española, significaron después la elaboración del Informe Quintana (1813) que fue la primera norma del Estado Liberal donde se desarrollo los principios constitucionales y en la cual no se tuvo en cuenta la educación de la mujer. No obstante, un año después, en el Proyecto de Decreto para el arreglo general de la enseñanza pública se establecía que eran necesarias escuelas públicas donde las niñas aprendieran a leer y escribir y también las tareas domésticas para dedicarse durante su edad adulta.

Con el inicio de la Guerra del Francés (1808-1814), algunas mujeres, sobretodo de clase burguesa, intervinieron públicamente: aprovisionando a los ejércitos, acogiendo heridos, actuando en la retaguardia e, incluso, defendiendo las ciudades con las armas como son los casos de Agustina de Aragón y Manuela Malasaña. 
Con el Trienio Liberal, y a raíz de la frecuentación de las mujeres en cafés y locales asociativos, se inició una disputa acerca de la presencia femenina en el ámbito público. En consecuencia, se abrió debate sobre el acceso de la mujer a Cortes a partir de los argumentos de algunos hombres que defendían que las mujeres debían adquirir mayores conocimientos de las leyes y de los principios por los cuales se regía la sociedad y así educar mejor a los ciudadanos (en masculino).

Pero, el retorno de Fernando VII, el año 1823, representó el retorno a un modelo absolutista paralizando la incorporación de la mujer en la educación y el ámbito público, puesto que el gobierno absolutista recortaba en proyectos educativos de niñas que no fomentaban las tareas domésticas y que pretendían instruirlas y no educarlas moralmente. Curiosamente, con su muerte, el año 1833, María Cristina y su hija Isabel II, dieron apoyo a los liberales para formar gobierno, fueron juzgadas por alejarse el concepto de feminidad de la época, por su actuación política y por su comportamiento en el ámbito privado.

Fue durante el periodo isabelino que se fue creando una red de beneficencia y que surgieron voces que ponían en tela de juicio el arquetipo de "Ángel del Hogar", que reivindicaban la discriminación del sector femenino por razones de sexo.

Aun así los cambios no fueron evidentes hasta 1868 cuando la implantación del liberalismo tomó un aire más democrático a raíz de la negociación de progresistas, demócratas exiliados antiisabelinos y unionistas en Ostende, el agosto de 1866, con el objetivo de acabar con el autoritarismo del gobierno de Narváez y que, a la vez, dejará a la reina Isabel II sin ningún tipo de apoyo. Este pacto fue el precedente del 19 de septiembre de 1868 en que parte del ejército, encabezado por el General Prim y Francisco Serrano, protagonizó un pronunciamiento que obligó a Isabel II a exiliarse. Este golpe de estado, sobretodo con la creación de las juntas revolucionarias en diferentes regiones, tomó un aire revolucionario.

A partir de aquí, unionistas y progresistas formaron un gobierno provisional (18681871), presidido por Francisco Serrano, en el cual no contaban ni con los demócratas ni con los republicanos. De todas maneras, a partir de aquí, el nuevo gobierno fue reconociendo nuevos derechos y principios de libertad que habían estado reclamados por las juntas revolucionarias como la implantación del sufragio universal masculino a partir de los 25 años (que hasta entonces únicamente había estado en manos de 1'1\% de la población), la libertad de culto y enseñanza y el reconocimiento del derecho de asociación. Además, y sobretodo a raíz de este último derecho, la apertura democrática del nuevo gobierno favoreció también a sectores como la masonería, que ya estaba en activo desde hacía años,

\footnotetext{
${ }^{1}$ Esta expresión se refiere a la mujer dulce y sensible, entregada a la domesticidad y a su rol como madre y esposa.
} 
y se vio notablemente aumentada, como indica el incremento de las logias y su reorganización ${ }^{2}$.

El nuevo contexto impulsó que las mujeres comenzaran a formar parte de la vida pública aunque la mayoría continuaron en el hogar. Es por ello que algunas mujeres empezaron a iniciarse en la masonería. La mayoría eran de sectores de la burguesía, porque tenían estrechas relaciones o estaban casadas con masones mientras que una minoría se iniciaba de manera individual ${ }^{3}$, haciendo que entre 1868 y 1900, más de 400 mujeres estuvieran vinculadas a la masonería en el estado español.

En este nuevo contexto y por iniciativa de los krausistas, defensores de la tolerancia académica e impulsores de las Conferencias Dominicales, se combatió la moral y la educación que dominaba en la sociedad, marcada por un gran control eclesiástico y gubernamental y se luchó por conseguir la educación femenina ${ }^{4}$ intentando alejarse, así, de los valores tradicionales otorgados al sexo femenino que predominaban durante el siglo XIX, como el amor, la paciencia, la discreción, la laboriosidad y la generosidad ${ }^{5}$. Aunque se promovieron diferentes iniciativas, durante el siglo XIX, la idea que prevalecía, entre los que abrazaban el liberalismo, era que la mujer complementaba al hombre; no era un individuo per se. Aun así, las diferentes posturas provocaron, a finales de siglo, un debate latente alrededor de la figura femenina ya que era una pieza clave en la formación moral de los ciudadanos (en masculino) y del cuidado del hogar, sobretodo a partir de la Revolución de la Gloriosa que dio más visibilidad a las mujeres y que fue el inicio de la ruptura del concepto de feminidad vigente hasta entonces. En este sentido, los seguidores de Charles Fourier ${ }^{6}$ argumentaron a favor de la emancipación femenina mientras que otros sectores, más tradicionales, sostuvieron que la mujer era un ser inferior por su naturaleza biológica y maternidad, que la condicionaba.

En definitiva, aunque hubo un proceso regenerador, el siglo XIX, con sus diversas constituciones, fue restrictivo con las mujeres porque cuando se empezó a legislar se hizo en pro de una educación que fomentaba el tradicional concepto de feminidad y que perpetuaba una estructura familiar y social bajo la dominación masculina ${ }^{7}$. Estas constituciones del siglo XIX excluyeron a la mujer y no fue hasta el año 1931, con el empuje de Clara Campoamor, que la mujer fue visible en campos como la vida política, el

\footnotetext{
${ }^{2}$ Pedro Alvárez Lázaro, La masonería, escuela de formación del ciudadano. La educación interna de los masones españoles en el último tercio del siglo XIX (Madrid: UPCo departamento de publicaciones, 2005), 127.

${ }^{3}$ Natividad Ortiz Albear, "Las mujeres en la Masonería Española (1868-1939)", REHMLAC 2, no. 4, (diciembre 2012-abril 2013), 76-88, https://revistas.ucr.ac.cr/index.php/rehmlac/article/view/12185/11468

${ }^{4}$ Anna Caballé, El feminismo en España. La lenta conquista de un derecho (Madrid: Cátedra, 2013), 120.

${ }^{5}$ Bonnie Anderson y Judith Zinsser, Historia de las mujeres: una historia pròpia (Barcelona: Crítica, 2000), vol. 1, 14-24.

${ }^{6}$ Charles Fourier fue uno de los impulsores del socialismo utópico el cual rechazaba y criticaba el liberalismo, la industrialización y el modelo tradicional de familia.

${ }^{7}$ Anderson y Zinsser, Historia de las mujeres, 25-30.
} 
ámbito jurídico, social, civil y penal y que obtendrá, por primera vez, el derecho a voto (sufragio universal).

\section{Masonería femenina}

Durante el siglo XIX, la masonería liberal ${ }^{8}$ fue la que empezó a plantearse la presencia de la mujer, aunque no arraigó hasta finales de siglo. Aun así fue sobretodo a partir de La Gloriosa ${ }^{9}$ que se fueron iniciando mujeres en las logias masculinas aunque las Constituciones de Anderson no contemplasen esa iniciación. De primeras, las mujeres que ingresaron lo hicieron a partir de ritos masculinos y eran mujeres que asistían regularmente a trabajos de las logias y que podían obtener cargos de responsabilidad, como se verá en los apartados posteriores ${ }^{10}$.

Cabe decir que muchos masones estaban a favor de que las mujeres obtuvieran derechos tanto en el ámbito privado como en el público y por ello apoyaran, por ejemplo, proyectos de educación para las mujeres aunque, en contraposición, algunos fueron reticentes al ingreso de la mujer en masonería y en la manera como lo debían hacer ya que, como ya se ha expuesto, las Constituciones de Anderson no contemplaban el ingreso de la mujer porque dependían de los hombres y, en definitiva, no eran consideradas personas libres.

Así, hubo mujeres que se iniciaron durante las últimas décadas del siglo XIX y a partir de la Revolución de La Gloriosa. La incorporación de la mujer en masonería, por tanto, fue consecuencia de los discursos de algunos masones que creían en la emancipación de la mujer y el impulso de algunas mujeres y defensoras de los derechos de las mujeres como Ángeles López de Ayala. Por poner un ejemplo, masones, como el escritor y político Cristóbal Litrán, defendieron en los Symposa la unión entre lo masculino y lo femenino como consecuencia de un discurso anticlericalista masón mientras que otros, como el naturalista Odón de Buen, pensaban que la iniciación de la mujer en masonería supondría la perfección de su rol como madre ${ }^{11}$. Esta idea de relacionar la mujer con la maternidad y con su papel en el hogar también fue sujetada por masonas como Mercedes Vargas de Cambó.

Como ya se ha mencionado, por tanto, el objetivo principal de la mayoría de masones era alejar a la mujer de la Iglesia y que ella pudiera asistir a las ceremonias después de sus tareas en el hogar, como hacían en la Iglesia. Estos propósitos, como son la

\footnotetext{
${ }^{8}$ Aquí se usa esta conceptualización para distinguir las dos grandes corrientes internas de la masonería, las cuales, aunque ambas sean liberales, se diferencian así porque tienen enfoques diferentes respecto a diferentes asuntos, como por ejemplo la presencia de la mujer en masonería.

${ }^{9}$ Ortiz Albear, Mujeres masonas en España. Diccionario Biográfico (1868-1939) (Santa Cruz de Tenerife: Ediciones Idea, 2007), 57.

${ }^{10}$ José Antonio Ferrer Benimeli, La masonería (Madrid: Alianza Editorial, 2005), 71.

${ }^{11}$ Ortiz Albear, Las mujeres en la masonería (Málaga: Universidad de Málaga, 2005), 106-108.
} 
desvinculación de la Iglesia como reforzadora de su rol como madre y esposa, responden a las reivindicaciones de la presencia de las mujeres en el ámbito social ya que las logias, como espacio de desarrollo social, se convirtieron en lugares de reunión y asociación de escritoras, novelistas, empresarias, poetas, entre otras. Sin embargo, las mujeres que querían iniciarse tuvieron que hacer frente a duras críticas, desde el exterior, por la mala reputación de la masonería, y desde el interior de esta, por su condición femenina.

Se puede afirmar, por tanto, que en los orígenes del movimiento por los derechos de las mujeres formaron parte las logias masónicas porque sus iniciados defendían la instrucción femenina, a través de la creación de escuelas, academias, asociaciones, entre otras, que fue uno de los primeros derechos que se promovió para la liberación de las mujeres y su integración en la sociedad. Además, a finales del siglo siguiente este movimiento cogió fuerza, a la vez que la mujer masona recibía educación en familia y fuera de ella para educar ciudadanos y ciudadanas (tanto su descendencia como alumnado) que acentuaban su autoestima y la hacían salir del ámbito privado con argumentos y valores humanistas como la igualdad, la fraternidad, la libertad y la laicidad.

En definitiva, la masonería se acercó a las mujeres a través de la educación la cual buscaba la perfectibilidad humana y, a su vez, era una manera de alejarla de la influencia de la Iglesia. A medida que este movimiento avanzaba, se abría un nuevo camino en la masonería, haciendo que la mujer crease un nuevo vínculo entre familia y $\operatorname{logia}^{12}$. Como M. José Lacalzada concluye, las mujeres masonas ingresaron en masonería con su rol de madres y esposas, aunque algunas fueron impulsando iniciativas para mejorar su autoestima y como seres individuales. Desde la masonería, por tanto, se criticaba el sistema clerical pero no el patriarcal ${ }^{13}$.

\section{Rito de Adopción}

Las primeras iniciaciones en masonería de las mujeres fueron en las logias masculinas aunque, más tarde y en algunos casos, se fueron disociando, creando logias femeninas o de adopción que dependían de una logia masculina. También había casos que sucedía a la inversa, es decir, mujeres que ingresaban en las logias de Adopción y pasaban después a las logias masculinas, pero eso a partir de inicios del siglo XX.

Es posible que, primeramente las mujeres ingresasen con el rito masculino prescrito y cuando había un gran nombre de mujeres en el taller se creaba la Logia de Adopción des de donde se podían mover dentro de la legalidad ${ }^{14}$. Pero, de todas formas, la Masonería de

\footnotetext{
${ }^{12}$ Ortiz Albear, Las mujeres en la masonería, 397-398.

${ }^{13}$ María José Lacalzada de Mateo, "Humanismo ilustrado-liberal en la emancipación de las mujeres y su engranje masónico en España", en Teoría feminista: de la Ilustración a la globalización, eds. Celia Amorós y Ana de Miguel (Madrid: Minerva, 2005), vol. 1.

${ }^{14}$ Ortiz Albear, Mujeres masonas en España, 69-70.
} 
Adopción nació en el estado español, pues, para frenar las iniciaciones de mujeres con ritos masculinos.

La primera Ley de Adopción en el estado español fue decretada por el Gran Oriente Español el 15 de agosto de 1892 donde, en relación al principio de igualdad, se regulaba el ingreso de la mujer en masonería en calidad moral y educadora. Eso se plasmó en los primeros estatutos del Rito de Adopción publicados en el año 1893 donde también se presentaban los derechos y los deberes de las mujeres iniciadas en masonería y el logro, como máximo, del grado de maestra masona ${ }^{15}$. Precisamente, las mujeres que se habían iniciado en el Rito Escocés Antiguo y Aceptado, podían conservar su grado como título honorífico o renunciarlo por su equivalente en este nuevo Rito de Adopción ${ }^{16}$.

A diferencia de las preguntas de iniciación de los hombres, que tenían un carácter más espiritual, las mujeres debían responder a preguntas más de corte doméstico como “¿Qué debemos a nuestros padres?", ¿Qué debemos a nuestro marido y a nuestros hijos?" y "¿Qué debemos a la amistad y a la sociedad?".

Evidentemente las mujeres para acceder en masonería necesitaban la autorización de su esposo o, en el caso de ser soltera, de su padre; tener una buena conducta, más de dieciocho años, medios de vida suficientes y haber estado propuesta por un taller quince días antes de la recepción ${ }^{17}$.

En síntesis, la posición de la mujer dentro de la masonería era subordinada ya que, por su condición, no podían acceder a los mismos grados que un hombre, aunque la falta de documentación hace difícil la reconstrucción ${ }^{18}$. Además, las Logias de Adopción dependían de las logias masculinas y, por tanto, obedecían estrictamente al Venerable Maestro de la logia masculina. Ahora bien, con la tolerancia de los hombres, la creación de logias femeninas significaba un gran avance hacia la emancipación femenina ${ }^{19}$ aunque no solucionó totalmente esta cuestión ya que, por ejemplo, las mujeres aparecen en los documentos censales, pero no en las actas de reunión y su papel, como se ha visto en las preguntas de iniciación, no rompía con su rol de madre y esposa.

\section{Logias de Adopción}

El aumento de la presencia de la mujer en las logias masculinas, siendo la primera registrada en la logia catalana Moralidad el año 1872, fue el causante de la creación de las logias femeninas o Logias de Adopción, como ya se ha dicho.

\footnotetext{
${ }^{15}$ Lacalzada de Mateo, "La mitad femenina "para" la masonería y "en” masonería (1868-1936). Balance y perspectivas", IH Revista 23 (2003): 117-139.

${ }^{16}$ Lacalzada de Mateo, El cimiento Mixto en Masonería. El derecho humano en España (1893-1963). (Madrid: Fundación Maria Deraismes, 2007), 51.

${ }^{17}$ Lacalzada de Mateo, "La mitad femenina", 117-139.

${ }^{18}$ Ortiz Albear, Mujeres masonas en España, 32.

${ }^{19}$ Ortiz Albear, Mujeres masonas en España, 35.
} 
Madrid fue una de las ciudades precursoras en la creación de Logias de Adopción que contaba con la Logia de Adopción Hijas de Minerva, que se estableció el año 1873 y que dependía de la logia Porvenir vinculada al Gran Oriente de España, la Logia Hijas del Sol, creada el año 1873, Hijas de Memphis, fundada el año 1877 e Hijas de los Pobres, fundada el año 1887, de la cual fue venerable Maestre Suceso Sánchez y en la cual se inició también Ángeles López de Ayala.

Paralelamente, la primera logia femenina en la zona de Cataluña, Baleares y Valencia fue la Cámara de Adopción dependiente de Lealtad n ${ }^{\circ} 78$, creada en Barcelona el año 1879 en la cual se inició Àurea Rosa Clavé, la hija de Anselm Clavé, y en 1881, Clotilde Cerdà. A partir de entonces se crearon la Logia de Adopción Creación $\mathrm{n}^{\circ} 2$ creada el año 1882 en Mahón, la Logia de Adopción Hijas de la Acacia de Valencia, que dependía de la logia Capitular Acacia n.25 y fue creada el 1890 de la cual era Venerable Maestra Júlia Fos, la Logia de Adopción Hijas de la Unión de Valencia, creada el año 1891, que dependía de Valencia n. 119 del Gran Oriente Español la impulsora de la cual fue Ángeles Sanmillán, que perteneció des de sus inicios a una logia masculina y la logia Constante Alona de Alicante que se creó en 1889 y en 1990 ya contaba con 21 iniciadas. Sin embargo, continuaba habiendo mujeres que se iniciaban en logias masculinas como Hermanos de la Humanidad, no. 32, que dependía del Gran Oriente Español y que fue creada entre 1884 y 1887.

En Andalucía, se crearon varias logias de este tipo. La logia Luz del Porvenir estaba vinculada al Gran Oriente Nacional de España y en ella se contabilizaron trece mujeres iniciadas entre 1888 y 1889, la logia América no. 27 de Ubrique fundada el 1889, que dependía del Gran Oriente Español y que perduró hasta la Segunda República, la Logia de Adopción Hijas de la Regeneración de Cádiz, que dependía del Gran Oriente Nacional de España y que se fundó el 1895 y tenía como afiliadas las feministas Amalia y Ana Carvia ${ }^{20}$, Audacia 90 en Herrera (Sevilla) creada como consecuencia de la implantación de la Gran Logia Simbólica Española de Memphis y Mizraim el 1889 y las logias Carteia, que pertenecía a la Gran Logia Simbólica Regional de Andalucía, e Hijas de la Luz, en Málaga, vinculada a la logia Luz de Málaga.

En la zona de Murcia, se constituyó la Logia Caridad, concretamente en Cartagena en el año 1893 a causa del numeroso grupo de mujeres que había en la logia Diez Hermanos no. 380 que estaba bajo el liderazgo del Gran Oriente Nacional de España.

En otras zonas, en cambio, las logias tuvieron poca actividad femenina como es el caso de Extremadura ya que solamente se han encontrado documentadas tres mujeres en los ritos masculinos, aunque una de ellas, Palmira, consiguió un grado 4 y Cancio un grado 7.

${ }^{20}$ Hago uso del término "feministas" porque, aunque en el siglo XX no se puede hablar de feminismo propiamente dicho, han sido conceptualizadas así en las diferentes obras de consulta. 


\section{Vidas masonas}

Para conocer la historia de la masonería femenina desde la Gloriosa hasta finales del siglo XIX, es interesante sumergirnos brevemente en la vida de algunas de las masonas más destacadas (con simbólicos relacionados con la inteligencia, la moralidad, el arte, e incluso, con la voluntad de autonomía) que lucharon por su dignidad y para que las mujeres tuvieran visibilidad más allá del espacio privado.

\section{Rosario de Acuña}

Rosario de Acuña, que el año 1886 se inició en la logia Constante Alona con el simbólico de Hipatia, fue una mujer ácrata que a través de su pertenencia a movimientos sociales y de la literatura denunció la situación de la mujer y de las personas desfavorecidas, en general. Defendía que las mujeres actuasen de manera regeneradora y que hubiera igualdad de derechos entre todas las personas. Fue Rosario de Acuña quien desarrolló un discurso rupturista con la Iglesia y el patriarcado con los argumentos de que hombres y mujeres eran almas gemelas con el objetivo de mejorar la humanidad como seres pensadores y sociales ${ }^{21}$.

\section{Amalia Carvia y Ana Carvia}

Amalia Carvia, profesora de pintura, y Ana Carvia, estudiante, se iniciaron el año 1887 en la logia Regeneración $n^{\circ} 118$ de Cadiz, que dependía del Gran Oriente de España, con el simbólico Piedad y Verdad, respectivamente. En esta logia consiguieron el 3er grado y, meses más tarde, fueron elegidas como "Orador Adjunto" y "Secretario Adjunto", respectivamente ${ }^{22}$.

En 1890 se trasladaron a Huelva donde participaron en la fundación de la logia Unión y Sinceridad, fusión entre las logias Unión y Sinceridad y Moralidad.

El 1895, las hermanas Carvia, juntamente con otros masones y masonas, como Jacinta Navarro Fonseca, Granada, construyeron Hijas de la Regeneración como logia femenina con iniciación a través del Rito Escocés desvinculándose del Rito de Adopción (que mantenía a la mujer en una posición de subordinación) bajo la tutela masculina ${ }^{23}$. Aunque fue una logia femenina, era habitual la presencia de hombres de diferentes logias y ellas eran convocadas para asistir a las iniciaciones de las logias masculinas. Hijas de la Regeneración no fue una logia de adopción propiamente dicha sino que orientaba a las mujeres en relación a su autonomía y autoestima, en concordancia con posturas protofeministas.

\footnotetext{
${ }^{21}$ Caballé, El feminismo en España, 126.

${ }^{22}$ Lacalzada de Mateo, El cimiento Mixto en Masonería, 81.

${ }^{23}$ Lacalzada de Mateo, "Humanismo ilustrado-liberal", 238.
} 
El año 1897 fundaron la Unión Femenina de Huelva, en la cual Ana era secretaria y Belén de Sárraga, presidenta, con el objetivo de acabar con la falta de intelectualidad entre las mujeres y acabar con la moralidad cristiana que regía sus vidas ${ }^{24}$. El mismo año fundaron la Asociación General Femenina de Valencia.

\section{Ángeles López de Ayala}

Ángeles López de Ayala fue una destacada librepensadora y espiritista y una de las pioneras del feminismo en Cataluña. El 1888 se inició en la logia madrileña Hijos del Progreso y el 1889 en la logia de adopción Hijas de los Pobres dependiente del GONE del Vizconde de Ros. Era una férrea defensora del ingreso de la mujer en masonería. Llegó a ser grado 30 y estuvo en la logia masculina Constancia de Gracia en Barcelona donde fue secretaria y oradora.

Fundó, el año 1898, juntamente con le escritora Amalia Domingo Soler i la anarquista Teresa Claramunt, también masonas, la Sociedad Progresiva Femenina ${ }^{25}$ que fue promotora de la escuela laica y defensora de planteamientos feministas provinentes de toda Europa.

\section{Belén de Sárraga}

Fue una de les primeras médicas españolas. Como defensora de ideales librepensadores, republicanos y feministas, replicó que la Iglesia era la principal fuente de retraso de la mujer ${ }^{26}$ defendiendo la libertad religiosa y la separación de la Iglesia y el estado. Se inició el año 1896 en la logia Severidad nº88 de Valencia, que dependía del Gran Oriente Ibérico, con el simbólico de Justicia. Un año después, fue nombrada "Gran Inspectora General, con la categoría de "Sublime Maestra", por lo que se encargaba de dirigir y organizar la masonería de mujeres dependiente de esta obediencia. Tuvo la misión de atraer a las mujeres a la masonería y a través de la cual promulgó los derechos políticos de las mujeres. Se marchó de España hacia otros lugares de Europa y Latinoamérica por las trabas que le pusieron para dedicarse a la escritura y a la propaganda ${ }^{27}$.

\section{Mercedes Vargas de Chambó}

Mercedes Vargas de Chambó, Juana de Arco, fue una escritora catalana que se inició en la logia Constante Alona de Alicante el 1883 y, más tarde, en la logia Humanidad

\footnotetext{
${ }^{24}$ Lacalzada de Mateo, El cimiento Mixto en Masonería, 83.

${ }^{25}$ Esta organización fue sustituta de la Sociedad Autónoma de Mujeres de Barcelona (1891) que luchaba por los derechos laborales y sociales de las mujeres y también por su autonomía.

${ }^{26}$ Caballé, El feminismo en España, 127-128.

${ }^{27}$ Sylvia Hottinger, "Un contexto para una masona, librepensadora, feminista y republicana: Belén de Sárraga (1872-1950)", REHMLAC 5, no. 1 (mayo-noviembre 2013): 143-159, https://revistas.ucr.ac.cr/index.php/rehmlac/article/view/10358/9747
} 
de Albacete. Defendía la iniciación de la mujer en masonería como educadora moral de la familia haciendo uso de un discurso donde la mujer era la principal influencia en el espacio privado, argumentando que era el primer paso hacia la emancipación femenina.

Como se ha plasmado en este apartado, algunas mujeres como Amalia y Ana Carvia, Bélen de Sárraga y Ángeles López de Ayala consiguieron cargos importantes en las logias y consiguieron altos grados en el Rito. Además, muchas de ellas fueron grandes defensoras de los derechos de las mujeres tanto en el ámbito masón como en el mundo profano. Es por eso que es trascendental buscar el origen del feminismo a través de su relación con el librepensamiento republicano, en el espiritismo y en la masonería.

\section{Feminismo del siglo XIX}

\section{Contexto europeo}

El desarrollo del capitalismo y la industrialización en Europa, a partir de la segunda mitad del siglo XIX, significó la ruptura de la relación entre trabajo y hogar, como lugar de consumo, y dio lugar a la remuneración económica a cambio del esfuerzo laboral. Eso comportó, a la vez, nuevas relaciones de producción, nuevos grupos sociales $\mathrm{y}$, en consecuencia, nuevas formas de explotación que provocaron desigualdades sociales las cuales afectaron a las clases populares y, en efecto, a las mujeres de estas.

Las revoluciones liberales americanas y francesa aspiraron a la igualdad universal, pero sin incluir en ésta al sector femenino ya que no se hacia mención de sus derechos. Incluso algunos pensadores como Jean-Jacques Rousseau reforzaron estereotipos misóginos y su subordinación ${ }^{28}$.

En consecuencia fueron surgiendo movimientos críticos como es el caso del socialismo y el anarquismo y también algunas voces críticas que preconizaban los derechos de las mujeres ya que la implantación del liberalismo no se concibió desde una perspectiva de género, como se ha comentado ${ }^{29}$. Estas sentarían las bases del feminismo del siglo XIX.

Esto supuso, durante el siglo XIX, la ampliación de manera progresiva de la formación de las mujeres, sobretodo de clase media y alta, que les permitió acceder a lugares de trabajo relacionados con el cuidado y la educación de los otros mientras que las mujeres de clase popular se fueron incorporando al sector ocupacional trabajando en fábricas textiles o tabaqueras o, incluso, en minas, con jornadas de hasta diez horas y sin cobertura legislativa. Además, muchas chicas sin recursos se vieron obligadas a dedicarse a la prostitución.

\footnotetext{
${ }_{28}^{28}$ Juan Sisinio Pérez Garcón, Historia del feminismo (Madrid: Catarata, 2011), 37-38.

${ }^{29}$ Pérez Garcón, Historia del feminismo, 59-67.
} 
Por tanto, el feminismo fue producto de cambios políticos, sociales y económicos en los países industrializados y, principalmente, en los grandes centros urbanos donde se fue cambiando el estilo de vida y, en consecuencia, la estructura social y familiar ${ }^{30}$. Estas diferentes circunstancias dieron lugar a diferentes feminismos en toda Europa durante el siglo XIX que iban desde defender el reconocimiento de las mujeres en el ámbito social y familiar a querer cambiar la legislación para establecer una igualdad entre sexos hasta el feminismo socialista que quería cambiar aquello relacionado con el ámbito laboral y atacaba la estructura familiar o el feminismo católico que buscaba mejoras en la educación, derecho de voto y más oportunidades laborales para las mujeres casadas.

\section{La educación, la base del avance en la emancipación de la mujer}

En Europa y en los Estados Unidos, desde la primera mitad del siglo XIX, se reivindicó la educación de la mujer como ser social ya que como afirma Geraldine Scanlon, la educación es el factor más importante para acabar con la sumisión y la ignorancia de la mujer $^{31}$ ya que la falta de esta, juntamente con la dependencia económica, era la que la hacia servil al hombre. Aun así, muchos consideraban esta reivindicación un peligro ya que, así, la mujer dejaba de lado el ámbito privado.

En el caso de España, Pablo Montesino, director de Instrucción de Primaria, ya el año 1835, argumentaba la importancia de la educación de la mujer porque era quien educaba su descendencia. Aun así, no fue hasta después de la Revolución La Gloriosa, de mano de los krausistas, que se pretendió educar a la mujer a través de conferencias y diferentes instituciones que tenían como objetivo su formación.

Fue entonces cuando se creó el Ateneo Artístico y Literario de Señoras de Madrid (1869), impulsado por Fernando de Castro, que fue una institución de enseñanza artística, religiosa y científica que buscaba instruir a las mujeres para que educasen a sus hijos como grandes ciudadanos y cabezas de familia. Lo hacía desde una perspectiva moralizadora sin alejar a la mujer de su rol como madre y esposa.

Meses más tarde, el mismo Fernando de Castro desde la Universidad Central, fue impulsando, paralelamente, la creación de las Conferencias Dominicales, dadas por hombres krausistas ${ }^{32}$, con el objetivo de reducir la tasa de analfabetismo. Entre los colectivos analfabetos, se encontraban un gran nombre de mujeres y es por ello que, desde esta, también se planteó la emancipación de la mujer y su alfabetización, sin distinción de

\footnotetext{
${ }^{30}$ Richard Evans, Las Feministas: los movimientos de emancipación de la mujer en Europa, América y Australia, 1840-1920 (Madrid: Siglo XXI, 1980), 38-43.

${ }^{31}$ Geraldine Scanlon, La polemica feminista en la España Contemporanea (1868-1974) (Madrid: Siglo XXI, Madrid, 1976), 25-35.

${ }^{32}$ Es una corriente filosófica, en base del pensamiento de K. Ch. F. Krause que buscaba un equilibro entre la moralidad y el racionalismo a partir de la educación.
} 
clases sociales, para, posteriormente, integrarla en el mundo social y laboral ${ }^{33}$. Estas conferencias pedagógicas trataban de temas diversos de economía domestica, historia, derecho, religión, salud, moralidad, pedagogía, ciencias naturales entre otras ${ }^{34}$ y las animaba a acceder a museos y bibliotecas de manera totalmente libre.

En consecuencia, el año 1870, también impulsado por Fernando de Castro y otros intelectuales (muchos de ellos provenientes de la masonería) fundaron la Asociación para la Enseñanza de la Mujer en Madrid y Barcelona, una iniciativa privada que también tenía el objetivo de educar e instruir a la mujer como ser social aunque mayoritariamente accedieron mujeres de la burguesía. Durante esta década fue cogiendo fuerza hasta que, en la década de los ochenta, se amplió su oferta de estudios. El medio de difusión de la Asociación fue La Instrucción para la Mujer (1882) dirigido por César Eguilaz donde se publicaban las actividades que se hacían, artículos informativos de temas generales para contribuir a la difusión del conocimiento y reseñas en relación a la educación de la mujer ${ }^{35}$. En acabar el siglo, la Asociación para la Enseñanza de la Mujer había contribuido a elevar de manera notable la instrucción de las mujeres, asumiendo un papel parecido al de la Institución Libre de Enseñanza, haciendo que hombres y mujeres trabajasen conjuntamente por este objetivo ${ }^{36}$. Paralelamente, el Ayuntamiento de Madrid comenzó a subvencionar la Asociación.

Este proyecto tuvo continuidad en el semanario Las Dominicales del Librepensamiento (1883-1909) donde colaboraron Odón de Buen, Miguel Morayta, Fernando Lozano, Rosario de Acuña, Amalia Carvia, Ana Carvia y Ángeles López de Ayala, que, como se ha visto en apartado anteriores, eran iniciados e iniciadas en masonería.

Además, durante esta década de los ochenta y la década siguiente se fueron ampliando, aunque no tuvieron tanta envergadura, la formación destinada a las mujeres de mano de otras entidades privadas, con gran vinculación con las anteriores, como la Escuela de Profesores de Párvulos, Escuela Primaria Elemental, Escuela Primaria Superior, Escuela Preparatoria, Escuela de Correos y Telégrafos, Escuela de Comercio y Escuela de Institutrices, las cuales ofrecían una formación liberal y científica alejada de la estatal donde se realizaban asignaturas destinadas a las tareas del hogar.

A la vez hubo una revitalización de la Escuela Normal por parte del Estado y la Escuela de Institutrices fundada, también, por Fernando de Castro aunque el Real Decreto

\footnotetext{
${ }^{33}$ Lacalzada de Mateo, Concepción Arenal. El enigma de la libertad. (Santander: Servicio de Publicaciones de la Universidad de Cantabria, 2006), 70.

${ }^{34}$ Lalcazada de Mateo, Concepción Arenal, 239.

${ }^{35}$ Lalcazada de Mateo, Concepción Arenal, 418-419.

${ }^{36}$ El año 1875 se construyó la Institución Libre de Enseñanza bajo el impulso del masón Francisco Giner de los Ríos, como un instituto libre, laico y con el soporte de la burguesía. Esta institución era librepensadora, republicana y krausista y defendía la enseñanza para las mujeres ya que era el método principal para regenerar la sociedad y establecer igualdades entre géneros y clases sociales, aunque no rompían con el modelo difundido por la estructura patriarcal.
} 
de 23 de febrero de 1883 reconoció las limitaciones de la Educación pública, frente a las iniciativas de carácter privado, ahora nombradas. A partir de aquí, con las reformas educativas del gobierno de Práxedes Mateo Sagasta, al cual daban apoyo los miembros de la Institución, se replanteó un cambio en el estilo de vida de las mujeres, incidiendo en sus derechos a la instrucción y a la enseñanza.

A partir de 1882, se impulsó congresos como el Congreso Nacional Pedagógico ${ }^{37}$, el Congreso Nacional, de 1888, de Barcelona donde se estableció la voluntad de que hubiera una enseñanza obligatoria de los seis a los doce años tanto para niños como para niñas o el Congreso Pedagógico Hispano-Luso-Americano, de 1892, en el cual se planteaba la educación en igualdad y profesional de ambos sexos y en el cual se inscribieron 528 mujeres.

En definitiva, fue a partir de las revoluciones liberales de los años treinta que se creyó que la mujer podía ejercer un nuevo papel como educadora de la ciudadanía. No obstante, no fue hasta después de la Revolución de La Gloriosa que hubo cambios importantes que sentaron les bases del protofeminismo a través de la lucha por la educación i la emancipación de la mujer. Fue sobretodo, como se ha visto, a partir de la segunda mitad del siglo XIX, y de la mano de proyectos privados impulsados por sectores como el krausismo, la masonería y el librepensamiento, que se avanzó en la enseñanza y la cultura femenina, aunque el modelo educativo continuó basándose en la domesticidad y que las mujeres de las clases medianas y altas se incorporaron en trabajos sociales y las mujeres de clase trabajadora, en el sistema de producción ${ }^{38}$.

\section{El derecho al trabajo, un derecho con limitaciones}

Los modelos culturales de género estipularon que la mujer, durante el siglo XIX, se tenía que dedicar a las tareas del hogar y su vida ociosa tenía que estar relacionada con la religiosidad. Asimismo, la Iglesia aprovechó su influencia moral y formó niñas y madres como seres morales haciendo que adoptasen un papel sumiso, honesto y piadoso, siguiendo las pautas de la moralidad cristiana. Por tanto, la mujer, según los arquetipos, estaba relacionada con la domesticidad que era lo que determinaba su función social y moral.

Aunque la vida domestica exigía total dedicación y la idea de relacionarla con el trabajo o con la vida pública era absurda, para muchos, a partir de la segunda mitad del siglo XIX, pero, diferentes sectores quisieron romper con estos estereotipos marcados por la religión cristiana. Por este motivo se gestaron nuevos conceptos de virginidad y fueron aumentando las voces críticas a cerca de la educación femenina establecida, el trabajo doméstico y la influencia de la religión en el sector femenino.

\footnotetext{
${ }^{37}$ Pilar Folguera, El feminismo en España. Dos siglos de historia (Madrid: Editorial Pablo Iglesias, 2007), 5459.

${ }^{38}$ Lalcazada de Mateo, Concepción Arenal, 419-424.
} 
En consecuencia, y a causa de la industrialización y la urbanización, se modificaron las estructuras económicas y sociales que afectaron al rol de la mujer, sobretodo a partir del siglo XX. La polémica a cerca del derecho al trabajo afectaba, especialmente, a las mujeres de clase media a la hora de realizar profesiones liberales ya que el estatus quo de las mujeres de clase baja no suponía ningún problema ni amenaza para el sector masculino. Tampoco era una amenaza si el trabajo que realizaba una mujer era una prolongación de las tareas que realizaban en casa como el magisterio o la asistencia a persones dependientes.

En el Congreso Nacional Pedagógico de 1882, que ya se ha citado anteriormente, muchos hombres eran partidarios de que las mujeres trabajasen en la enseñanza de parvulario, ya que explicaban que era una extensión de su tarea materna, o también en trabajos relacionados con la medicina, la enfermería o la farmacéutica, en la cual se debían seguir las instrucciones de las recetas, como lo hacían en la cocina. Una minoría, durante este período, consiguió una posición importante dentro de la profesión.

Otras se dedicaban a coser a domicilio pero estaba mal pagado e, incluso, muchas preferían el trabajo en la fábrica textil. En los años noventa del siglo XIX la mujer española obtenía menos remuneración que las costureras extranjeras, de las cuales preferían los tejidos las clases altas. Otras se dedicaban a la prostitución para afrontar las necesidades de la vida. Es por ello que Concepción Arenal, por ejemplo, intentó promover la lucha contra la abolición de esta (de la cual buscaban la legalización los sectores más progresistas de la época) con la creación de la Federación Abolicionista, que no tenía ninguna vinculación con ninguna filosofía, ideología y religión y únicamente quería abrir paso a la emancipación femenina en toda Europa a través del trabajo. Ésta tuvo el apoyo de la masonería.

En definitiva, el rol de la mujer se identificaba con su papel como madre, esposa y administradora del hogar. Desde esta perspectiva era inaceptable la remuneración al sector femenino en el mercado laboral porque, de esta manera, no podían desarrollar les tareas del hogar. Además, en este sentido, las tareas remuneradas se consideraron complementarias a las del trabajo masculino ya que la independencia económica de las mujeres suponía una subversión al modelo familiar y al dominio masculino. Además, las que trabajaron fuera del hogar, continuaron realizando tareas que no rompían con su rol como madre y esposa.

\section{La figura de Concepción Arenal, estudio de caso}

Es fundamental referirse a Concepción Arenal como una de las figuras impulsoras que puso las bases del feminismo en España durante el siglo XIX y que se desarrollaría a inicios del siglo XX. Como se ha visto a lo largo de este trabajo, la lucha por los derechos de las mujeres durante este siglo ha estado muy vinculada con los círculos librepensadores, krausistas y masones. Es por eso que se pretende incidir en la relación de Concepción 
Arenal con estos círculos, especialmente con la masonería, en la lucha de los derechos de la población femenina. Asimismo, esta cuestión se abarcará a partir del pensamiento y de las colaboraciones de Concepción Arenal en los proyectos que participa con estos sectores.

\section{El pensamiento de Concepción Arenal}

Concepción Arenal, preocupada por la religiosidad, pero no sometida a las directrices ortodoxas, bebió del espíritu liberal, de la burguesía liberal y del "doctrinarismo" 39 , el cual se alejó de sus propósitos emancipadores con la llegada del moderantismo al poder. Concepción Arenal creía en la libertad de pensamiento, en la adecuación de la legislación a los nuevos tiempos, en la razón, la libertad y la justicia.

Concepción Arenal sentía admiración por el krausismo, y a la inversa, y se nota una cierta influencia de este en su pensamiento por su tendencia humanista desde una perspectiva social, pedagógica y ética. Cabe decir, pero, que aunque fue heredera de este, no fue krausista ${ }^{40}$. No se sumó a ninguna corriente proveniente de la Ilustración aunque bebió de esta en el nuevo contexto político, intelectual y de desarrollo del liberalismo económico, relacionándose así con un humanismo ilustrado liberal y socialista posibilista que estaba en penumbra. Únicamente buscó valores universales, a través de las leyes de la naturaleza, para favorecer el desarrollo libre de las personas y las sociedades ${ }^{41}$. Es por este motivo que nunca fue perseguida, aunque quizá sí censurada.

Concepción Arenal dedicó su vida a reivindicar los derechos de las personas más vulnerables. Es por ello que defendió los derechos de las mujeres haciendo que se tomara conciencia de estas como persona ya que creía que la humanidad, tanto hombres como mujeres, era la que alimentaba el progreso en esta sociedad de cambios. Por este motivo intentó poner a muchos intelectuales de su parte argumentando que ellos serían los primeros en beneficiarse de la obtención de derechos de sus mujeres.

A lo largo del siglo XIX, se ve como el modelo liberal, en favor de la libertad y la igualdad, se contradice ya que las mujeres tuvieron que luchar para conseguir su emancipación ${ }^{42}$ aunque muchos de los discursos sobre su emancipación reforzaron su rol como madre y esposa, sin atacar verdaderamente a la estructura patriarcal. Fue Concepción Arenal, juntamente con algunas como Emilia Pardo Bazán, Rosario de Acuña, Ángeles López de Ayala, entre otras, las que fueron impulsando y fueron consiguiendo cambios en las capacidades y derechos de las mujeres puniendo las bases del feminismo que se desarrollaría en el siglo XX.

\footnotetext{
${ }^{39}$ Este tiene como principio el dominio de la naturaleza humana desde la cual se inicia el diálogo interpersonal de las relaciones sociales con el marco político y legislativo.

${ }^{40}$ Aurélie Pirat, "Concepción Arenal y el krausismo", Moenia 10 (2004): 355-373.

${ }^{41}$ Lalcazada de Mateo, Concepción Arenal, 491-493.

${ }^{42}$ Ana Castro Antonio, El pensamiento de Concepción Arenal (Trymar: Vigo, 2010), 40-41.
} 
Trató sobre la cuestión femenina por primera vez en La mujer del porvenir (1869) donde dignificaba a la mujer como persona, la integraba en su entorno como individuo y la pretendía incorporar en el mundo laboral, social, familiar y religioso ${ }^{43}$. En su siguiente obra publicada en relación a la condición de la mujer, La mujer de su casa (1883), explicaba que buscar la perfección de la mujer en el ámbito doméstico no era sinónimo de progreso. En esta obra fue más allá que en la anterior ya que hizo un análisis desde una perspectiva más crítica y, además, tenía el apoyo de feministas de otros lugares de Europa y sobretodo de América. Es decir, en esta obra intentó romper con los argumentos de los sectores más católicos que defendían que la mujer debía de dedicarse únicamente a la domesticidad ${ }^{44}$.

Concepción Arenal incluso afirmó que la mujer era moralmente superior al hombre ya que era más bondadosa y sensible y que su relación de dependencia, sobretodo económica, con el hombre y la falta de educación la dejaban en una posición de subordinación ${ }^{45}$ que, según Concepción Arenal, no favorecía al hombre ya que este era el primer interesado en tener a su lado una mujer fuerte y perfecta para que la sociedad progresara.

En definitiva, a lo largo de su vida, mostró respeto a la mujer del hogar y sostuvo la importancia de la lucha de derechos de las mujeres en aquella nueva sociedad moderna en que la mujer había de formar parte de la vida pública; tenía una misión social. Concepción Arenal, a partir de las ideas de perfectibilidad y concienciación, reclamó cambios en la vida familiar, social y laboral centrándose en la razón y la sensibilidad como bases para conseguir un equilibrio interior que se debía ampliar a partir del conocimiento y la moralidad.

\section{Colaboraciones con círculos masones y librepensadores}

Concepción Arenal trabajó en colaboración con masones, librepensadores y krausistas en calidad de defensora de una naturaleza más digna para las mujeres y aquellas personas desfavorecidas que vivían en la miseria.

Algunas expertas como Yolanda Alba afirman que el punto de partida de la colaboración de Concepción Arenal con la masonería empieza con la iniciación en esta de su padre. Sin embargo es conveniente mantener una cierta perspectiva delante de estos planteamientos ya que, por ejemplo, la experta en masonería y en la figura de Concepción Arenal, María José Lalcalzada, expone que no se puede afirmar firmemente la iniciación de su padre en masonería por la falta de documentos que lo manifiesten ${ }^{46}$.

\footnotetext{
${ }^{43}$ Lalcazada de Mateo, Concepción Arenal, 235-237.

${ }^{44}$ Lalcazada de Mateo, Concepción Arenal, 416-417.

${ }^{45}$ Lalcazada de Mateo, Concepción Arenal, 233.

${ }^{46}$ Yolanda Alba, Masonas: hisoria de la masonería femenina (Córdoba: Almuzara, 2014), 87.
} 
Algunas fuentes, que no han contrastado ninguna información con ningún documento verídico y riguroso, afirman que Concepción Arenal se inició en masonería y aunque la verdad es que, como ha plasmado María José Lacalzada en sus diversos trabajos sobre ella, no se tiene constancia que fuera iniciada en ninguna logia. Cabe decir, pero, que sí que colaboró con la logia las Hijas del Sol, dirigida por la baronesa Wilson, que estaba vinculada a la logia Los Hijos del Trabajo del Gran Oriente de España, y que sus escritos fueron recomendados en el Boletín Oficial del Gran Oriente de España el diciembre de 1872, los cuales se publicaron también en la "Voz de la Caridad". Además, lo que sí está claro es que, a partir los años cincuenta, cuando Concepción Arenal apoyaba éticamente y racionalmente a alguna de sus amistades impulsoras de la regeneración de la sociedad, colaboró con masones y librepensadores como Francisco Giner de los Ríos y Gumersindo de Azcárate. También recibió influencia de la Institución Libre de Enseñanza en la cual participaban masones y masonas y krausistas y de la Asociación Abolicionista Española para hacer desaparecer la esclavitud en las colonias españolas donde también se añadieron algunas masonas como Pilar Amandi de Ozores.

Después de su muerte, también se publicaron sus artículos en la "Conciencia Libre" que estaba ligeramente relacionada con el espiritismo. Esta revista, el año 1896, hizo un número extraordinario para sacar de la cárcel a la fundadora de ésta, Belén Sárraga que, como ya he comentado, era masona. Además, en esta, aparecía algún símbolo masón como la escuadra y el compás y tenía como colaboradoras habituales a las masonas Amalia de Carvia y Ángeles López de Ayala ${ }^{47}$.

Los escritos de Concepción Arenal estaban enfocados a dar soluciones prácticas a cerca de aquellas personas que vivían en la miseria, las mujeres, los niños abandonados, los obreros y los presos, objetivo, a menudo, de proyectos impulsados por sectores librepensadores, masones y krausistas. Por ese motivo, la perspectiva de Concepción a cerca de cuestiones sociales, hizo que tuviera apoyo en sus acciones de este tipo de sectores.

En resumen, Concepción Arenal siempre se situó en el terreno racional y mostró, a la vez, su capacidad de freno en el surgimiento de pasiones políticas y confesionales; motivo por el cual tuvo relaciones con amplios y diferentes círculos ideológicos y confesionales, sin estar adherida en ninguno de ellos.

\section{Conclusiones}

Suponía una gran dificultad el estudio de la reivindicación de los derechos femeninos del siglo XIX en España, como primer intento tímido de la superación de obstáculos en la educación y el analfabetismo de las mujeres, por el hecho de que surgieron diferentes voces críticas independientes, y no amplios grupos, como se estaba gestando por

\footnotetext{
${ }^{47}$ Lalcazada de Mateo, Concepción Arenal, 66-67.
} 
entonces en otros lugares de Europa. Por este motivo, para hacer una reflexión sobre el rol de la mujer y la lucha de sus derechos, ha estado imprescindible introducirse en la vida de personas concretas. Es en este momento, y a partir de la lectura de sus biografías, cuando se pone de manifiesto que muchas de ellas tenían una estrecha relación con círculos librepensadores, krausistas y masones. Por tanto, a partir de aquí, era de una gran importancia buscar los vínculos entre las bases del feminismo del siglo XIX y la masonería, especialmente a partir de la revolución de La Gloriosa, como período de apertura democrática y de desarrollo con más o menos libertad de esta sociedad secreta.

Resulta curioso que cuando comencé a profundizar en la vinculación de la masonería y el primer "movimiento" de reivindicación de los derechos de las mujeres en el siglo XIX en el Estado español, observé que, en la mayor parte de obras de expertos como, por ejemplo Ferrer Benimeli, se dedicase un reducido espacio (muchas veces no llegaba ni a una página) al estudio de género de la masonería. A saber, en pocas obras de masonería, en general, he localizado apartados donde se tratara de las Cámaras de Adopción y, aún menos, donde se estudiara, ni siquiera se mencionara, mujeres que marcaron un antes y un después en la masonería del siglo XIX.

Dicho esto, los discursos desarrollados por los masones se sostenían sobre argumentos anticlericales, es decir, los masones intentaban acabar con la influencia de la iglesia como principal difusora de la moralidad cristiana sobre las mujeres, y buscaban el perfeccionamiento de la mujer en su rol como madre y esposa en calidad de educadora moral de la ciudadanía. De esta manera, los razonamientos argumentados por los masones no rompían con el modelo patriarcal, que significaba el desarrollo del dominio masculino en detrimento del poder femenino, ya que, así, la mujer continuó teniendo un rol marcado por la domesticidad y la sumisión al género masculino. Cabe decir que, aunque la masonería no rompió con el modelo patriarcal, sí reivindicó que la mujer debía conseguir un papel como ser social, ya que ésta preconizaba la importancia de la relación del individuo con la sociedad y es por eso que creó proyectos y dio soporte a otros para alfabetizar y educar a las mujeres y que estas pudiesen educar a la ciudadanía para vivir en sociedad. Nuevamente, se puede observar que la figura de la mujer se orientaba no al perfeccionamiento como individuo sino como educadora de la ciudadanía; un rol que era la prolongación de su tarea en el hogar.

El espacio de desarrollo de este ser social en masonería tenía lugar en las logias, donde se reunían y asociaban las personas iniciadas. Inicialmente, en estas era rechazada la presencia de las mujeres, sobretodo en la masonería regular, ya que, según las Constituciones de Anderson, las mujeres no podían acceder a ellas porque no eran persones libres. Pero a raíz de discursos favorables al ingreso de la mujer en las logias masonas, sobretodo desde la masonería liberal, se permitió la iniciación de ellas en masonería. Aun así, se observó en el Estado español el aumento de las mujeres iniciadas a través de ritos masculinos, y se quiso frenar intentando crear la Masonería de Adopción, la cual dependía 
de las logias masculinas. En definitiva, el ingreso de la mujer supuso un avance hacia su emancipación aunque con restricciones ya que aparecían en los censos pero no en las actas de las reuniones y se crearon logias femeninas subordinadas a las masculinas. Igualmente, se puede observar, a través de las preguntas del rito de iniciación, que su ingreso estaba enfocado a un papel como educadora de la ciudadanía, especialmente del género masculino. Aun así, algunas de las más destacadas masonas, como se ha mencionado en el apartado correspondiente, buscaron el camino hacia la emancipación de la mujer a partir de la lucha por la dignidad, la visibilidad de las mujeres en el ámbito público y la igualdad de derechos en un contexto de apertura a raíz de la revolución democrática de 1868. Es por ello que Belén de Sárraga, las hermanas Carvia, Ángeles López de Ayala, Amalia Domingo Soler, Teresa Claramunt, entre otras, fueron las impulsoras de los tres centros más importantes del protofeminismo del siglo XIX como son la Unión Femenina de Huelva, la Sociedad Progresiva Femenina de Barcelona y la Asociación General Femenina de Valencia. Además, todas fueron unas grandes defensoras del ingreso de la mujer en masonería como medio.

Desde los sectores liberales, se apostó por la educación como pilar fundamental para acabar con la ignorancia y la sumisión del sector femenino de la población. Fue, también, a partir de la revolución de 1868, que krausistas, masones y librepensadores, desde proyectos privados, se propusieron alfabetizar a las mujeres para que se pudieran desarrollar como educadoras morales y seres sociales $y$, en consecuencia, orientarse al nuevo mercado laboral fruto de la revolución industrial y el nuevo sistema de explotación económica capitalista. Sin embargo, este rol de género, que no tenía un objetivo rupturista, hizo que las mujeres que obtenían remuneración, la consiguieran a partir de tareas continuistas y no alejadas a aquellas que desarrollaban en el espacio doméstico. En ese aspecto, también se desarrollaron legislaciones discriminatorias y una dependencia económica que impidieron una subversión al núcleo familiar y a la supremacía masculina.

Buena parte de las mujeres más influyentes que buscaban la emancipación de la mujer fueron iniciadas en masonería. Cabe decir, pero, que no siempre fue así, al menos no siempre se puede corroborar que así sea. Este es el caso de Concepción Arenal de la cual no se tiene constancia de que se hubiera iniciado en ninguna logia sino que únicamente colaboró con círculos masones, y también librepensadores y krausistas por el hecho de que reivindicaban derechos e ideas similares. Por tanto, parece ser que el protofeminismo y la masonería, entre los años 1868 y 1900, se retroalimentaron, como se observa a partir de las publicaciones sobre los derechos de las mujeres de Concepción Arenal en medios de difusión masones y su participación en proyectos e instituciones encabezadas por el sector masón. Es, por tanto, a través del desarrollo de un proceso colaborador, de algunos sectores de la masonería y de voces críticas con la estructura social, política y económica del momento, que se pusieron las bases del feminismo, como movimiento de reivindicación de los derechos y las capacidades de las mujeres, que empezaría a desarrollarse con fuerza a partir del primer tercio del siglo XX. 


\section{Bibliografia}

Alba, Yolanda. Masonas: hisoria de la masonería femenina. Córdoba: Almuzara, 2014.

Alvárez Lázaro, Pedro. La masonería, escuela de formación del ciudadano. La educación interna de los masones españoles en el último tercio del siglo XIX. Madrid: UPCo departamento de publicaciones, 2005.

Anderson, Bonnie y Judith Zinsser. Historia de las mujeres: una historia pròpia. Barcelona: Crítica, 2000.

Arenal, Concepción. La mujer del porvenir. La mujer de su casa. Barcelona: Ediciones Orbis, 1989.

Butinyà i Hospital, Francesc Xavier. Una Visió de la dona catalana en el segle XIX. Barcelona: Rafael Dalmau, 1982.

Caballé, Anna. Una Breve historia de la misoginia : antología y crítica. Barcelona: Lumen, 2006.

Caballé, Anna. El feminismo en España. La lenta conquista de un derecho. Madrid: Cátedra, 2013.

Campo Alange, María. Concepción Arenal. 1820-1893. Estudio biográfico documental. Madrid: Revista de Occidente, 1973.

Castro Antonio, Ana. El pensamiento de Concepción Arenal. Vigo: Trymar, 2010.

Evans, Richard. Las Feministas: los movimientos de emancipación de la mujer en Europa, América y Australia, 1840-1920. Madrid: Siglo XXI, 1980.

Ferrer Benimeli, José Antonio. La masonería. Madrid: Alianza Editorial, 2005.

Ferrer Benimeli, José Antonio. La Masonería en la España del siglo XIX. Salamanca: Junta de Castilla y León, y Valladolid: Consejería de Educación y Cultura, 1989.

Folguera, Pilar. El feminismo en España. Dos siglos de historia. Madrid: Editorial Pablo Iglesias, 2007.

Gómez-Ferrer, Guadalupe. Historia de las mujeres en España, siglos XIX y XX. Madrid: Arco Libros, 2011.

Hottinger, Sylvia. "Un contexto para una masona, librepensadora, feminista y republicana: Belén de Sárraga (1872-1950)". REHMLAC 5, no. 1 (mayo-noviembre 2013): 140164. https://revistas.ucr.ac.cr/index.php/rehmlac/article/view/10358/9747

Lacalzada de Mateo, María José. Mujeres en masonería : antecedentes históricos entre las luces y las sombras : 1868-1938. Premià de Mar: Clavell Cultura, 2006.

Lacalzada de Mateo, María José. Concepción Arenal. Mentalidad y proyección social. Zaragoza: Prensas Universitarias de Zaragoza, 2012.

Lacalzada de Mateo, María José. Concepción Arenal. El enigma de la libertad. Santander: Servicio de Publicaciones de la Universidad de Cantabria, 2006. 
Lacalzada de Mateo, María José. El cimiento Mixto en Masonería. El derecho humano en España (1893-1963). Madrid: Fundación Maria Deraismes, 2007.

Lacalzada de Mateo, María José. "La mitad femenina "para" la masonería y “en" masonería (1868-1936). Balance y perspectivas". IH Revista 23 (2003): 117-139.

Lacalzada de Mateo, María José. La Otra mitad del género humano: la panoràmica vista por Concepción Arenal (1820-1893). Málaga: Universidad de Málaga, 1994.

Nash, Mary. Mujeres en el mundo: historia, retos y movimientos. Madrid: Alianza, 2012.

Nash, Mary. Experiencias desiguales: conflictos sociales y respuestas colectivas: siglo XIX. Madrid: Síntesis, 1994.

Ortiz Albear, Natividad. "Las mujeres en la Masonería Española (1868-1939)". REHMLAC 4, no. 1 (diciembre 2012-abril 2013): 76-88. https://revistas.ucr.ac.cr/index.php/rehmlac/article/view/12185/11468

Ortiz Albear, Natividad. Las mujeres en la masonería. Málaga: Universidad de Málaga, 2005.

Ortiz Albear, Natividad. Mujeres masonas en España. Diccionario Biográfico (188-1939). Santa Cruz de Tenerife: Ediciones Idea, 2007.

Pérez Garzón, Juan Sisinio. Historia del feminismo. Madrid: Catarata, 2011.

Pirat, Aurelié. "Concepción Arenal y el Krausismo". Moenia 10 (2004): 355-373.

Presmasnes Garcia, Rosa Elvira. La Masonería femenina en España: dos siglos de historia por la igualdad. Madrid: Catarata, 2012.

Sánchez i Ferrer, Pere. La Maçoneria a Catalunya: 1868-1947. Premià de Mar: Clavell Cultura, 2008.

Scanlon, Geraldine. La polemica feminista en la España Contemporanea (1868-1974). Madrid: Siglo XXI, 1976.

Solé Romeo, Gloria. Historia del feminismo: siglos XIX y XX. Pamplona: Eunsa, 2011.

Varela, Núria. Feminismo para principiantes. Barcelona: Ediciones B, 2008.

Varios Autores. Teoría feminista: de la Ilustración a la globalización. Editado por Celia Amorós y Ana de Miguel. Madrid: Minerva, 2005. 